\title{
Resistencia inducida a la enfermedad del añublo de la panícula del arroz inoculando bacterias endofiticas
}

\section{Resistance induced to blight disease of rice panicle by inoculating endofiticas bacteria}

\author{
Resistência induzida à doença da panela do panicol \\ por inoculação de bactérias endofiticas
}

\author{
Manuel José Peláez Pelaez¹ \& Sandra Ximena Vivas Londoño² \\ 1'Ingeniero Agrónomo, Magister en Fitopatología, Doctor en Protección de Cultivos. \\ ${ }^{2}$ Ingeniera Agrónoma, Candidata a Magister en Ciencias Agrarias \\ 1,2 Universidad Nacional de Colombia. Palmira, Colombia \\ 1mjpelaez@unal.edu.co, 2svivasl@unal.edu.co
}

\section{Resumen}

Se evaluó el efecto antagónico de las bacterias endófitas aisladas de porciones de hojas, tallos y raíces de plantas de arroz completamente sanas, contra la bacteria patogénica Burkholderia glumae (Kurita \& Tabei, 1967), agente causal de la enfermedad del añublo bacterial de la panícula. Se obtuvieron 24 aislamientos en total de bacterias endófitas que fueron evaluadas mediante la técnica de enfrentamiento de cultivos duales, en condiciones de laboratorio, posteriormente se realizaron las inoculaciones de la solución bacteriana en condiciones de campo para evaluar el efecto antagónico. Los resultados obtenidos indican que sólo dos cepas bacterianas presentaron actividad antagónica contra B. glumae las cuales fueron identificadas mediante caracterización bioquímica, de los bioensayos realizados a nivel de laboratorio y en campo. Por tanto, hubo una mejor expresión de las bacterias antagónicas bajo condiciones controladas en el laboratorio comparado con los ensayos realizados en campo.

Palabras clave: añublo bacterial, bacterias endófitas, bioensayos, biopelículas.

\section{Abstract}

The antagonistic effect of the bacteria endófitas isolated from portions of leaves, stems and roots of completely healthy rice plants, against the bacterium pathogenic Burkholderia glumae (Kurita \& Tabei, 1967), causal agent of the disease of blight bacterial panicle it was evaluated. 24 isolates in total of endófitas bacteria that were evaluated by the technique of confrontation of dual cultures they were obtained, under laboratory conditions, then the inoculations of the bacterial solution were carried out in conditions of field to evaluate the antagonistic effect. The results obtained indicate that only two bacterial strains showed antagonistic activity against $B$. glumae which were identified by biochemical characterization of the bioassays performed at the laboratory and field level. Therefore, there was a better expression of antagonistic bacteria under controlled conditions in the laboratory compared to field trials.

Key-words: blast bacterial, endófitas bacteria, bioassays, biofilms. 


\section{Resumo}

O efeito antagônico das bactérias endofíticas isoladas de porções de folhas, hastes e raízes de plantas de arroz completamente saudáveis foi avaliado contra a bactéria patogênica Burkholderia glumae (Kurita \& Tabei, 1967), agente causal da doença bacteriana da praga bacteriana. Um total de 24 isolados de bactérias endofíticas foram obtidos, que foram avaliados utilizando a técnica de desafio de culturas duplas, em condições laboratoriais, e as inoculações da solução bacteriana foram realizadas em condições de campo para avaliar o efeito antagonista. Os resultados obtidos indicam que apenas duas cepas bacterianas mostraram atividade antagonista contra B. glumae, que foram identificados por caracterização bioquímica de bioensaios realizados em laboratório e campo. Assim, houve uma melhor expressão da bactéria antagonista em condições controladas no laboratório em comparação com ensaios de campo.

Palavras chave: bactéria bacteriana, bactérias endofíticas, bioensaios, biofilmes.

\section{Introducción}

La enfermedad del añublo de la panícula del arroz fue reportada por primera vez en el distrito de Kyushu en Japón por (Goto \& Ohata, 1956). Hoy en día este patosistema (Burkholderia glumae-Oryza sativa) (Shajahan et al., 2000), es el principal problema epidémico en diferentes partes del mundo Taiwán (Chien et al., 1984), Vietnam (Trung et al., 1993), Sri Lanka, Malasia, Las Filipinas (Cottyn et al., 1996), Nepal (Nieves,1999), Korea (Jeong et al., 2003), en Estados Unidos en los estados de Louisiana, Arkansas y Texas, (Nandakumar et al., 2005), Panamá (Nandakumar et al., 2007), Indonesia, Tailandia, Tanzania (Zhu et al., 2008), Cambodia (Cother et al., 2010), Venezuela (González et al., 2011) y Colombia (Zeigler \& Álvarez,1989).

En Colombia, hay reportes en el año 2009, que, durante el fenómeno del niño en el Pacífico, esta enfermedad causo estragos económicos en diferentes zonas arroceras ocasionando disminución en rendimiento tanto en volumen y producción, en los departamentos de Tolima y los Llanos orientales (León \& Aristizábal, 2011). La sintomatología del añublo de la panícula se presenta al iniciar el momento de la floración en la antesis, provocando espiguillas vanas (Cho et al., 2007), generando una decoloración en la parte basal de la vaina, la cual avanza rápidamente, hasta afectar la totalidad de la misma (Nieves, 1999), se presentan lesiones alargadas y verticales de color grisáceo, rodeadas por un margen de color marrón rojizo oscuro (Nandakumar et al., 2009). Los granos infectados en ocasiones se observan dispersos en la panícula, presentando síntomas severos como vaneamiento (Ou, 1985) y decoloración acentuada (Mogi, 1988). Una de las características más notorias de la enfermedad se observa en el raquis el cual presenta un color verde más intenso que el color normal de la planta, el raquis permanece erecto, no se produce llenado de los granos y por lo general presentan un color marrón, cuando se presenta un estado avanzado de la enfermedad se observa que la panícula se mantiene erecta (Yang, 2004; Sayler \& Yang, 2006). La enfermedad es de gran impacto económico, generando pérdidas de alrededor del $40 \%$ de la producción de los cultivos de arroz, en diversas partes del mundo (Iwai et al., 2002).

Hasta el momento se han adoptado diferentes estrategias de manejo, para el control de la enfermedad, como: resistencia genética, utilizando variedades resistentes, pero los cultivos comerciales son susceptibles al ataque de $B$. glumae, en diferentes grados (Shajahan et al., 2000; Saichuck et al., 2011). Control químico, se ha demostrado que algunas cepas bacterianas pueden llegar a obtener resistencia con el uso frecuente de estos productos en las plantaciones de arroz. Por tanto, se hace necesario adoptar nuevas técnicas de control que estén encaminadas a reducir el crecimiento y desarrollo de la 
enfermedad y así mismo minimizar el impacto ambiental generado por las actividades de control convencionales. Existen dos tipos de control alternativos como son: control cultural mediante el manejo óptimo del cultivo reduciendo el uso de aplicaciones de productos químicos, realizando siembras en épocas del año que no favorezcan la aparición del patógeno y el manejo adecuado de los residuos de cosecha. Otra técnica utilizada es el control biológico, que se encuentra como una de las alternativas más viables, y abarca la utilización de las bacterias endófitas como agentes de control benéfico contra la aparición de plagas y enfermedades, estas bacterias presentan una asociación biológica y se ubican en los tejidos internos vivos de las plantas, sin ocasionar ningún daño fitopatológico (Hallman et al., 1997) Trabajan como reguladoras promoviendo el desarrollo y crecimiento vegetal, les proporcionan a las plantas resistencia mediante la liberación de sideróforos, los cuales le permiten asimilar ciertos elementos mayores y menores, como el fosforo. Son capaces de inhibir el crecimiento y ataque de ciertos agentes fitopatógenos (Hernández et al., 2004). Los géneros más destacados en el cultivo de arroz son: Azospirillum (Thakuria, 2004), Herbaspirillum (Elbeltagy et al., 2001).

Algunas son formadoras de biofilms, y ayudan a la planta a regular los cambios de $\mathrm{pH}$, estrés osmótico, y la perdida de agua (Fleming et al, 1993; Gilbert 1997). Las biopelículas forman una alta acidez, generando una gran producción de IASD, importante para el control de patógenos. Algunas de estas son utilizadas para la introducción de algunos microorganismos benéficos en las plantas para el biocontrol de muchas enfermedades (Jayasinghearachchi et al., 2006). Con el fin de determinar si algunas bacterias endófitas tienen efecto antagónico sobre el crecimiento de un agente fitopatógeno, es necesario realizar bioensayos a nivel de laboratorio, para luego ser evaluadas en campo, una de las técnicas más utilizadas son los cultivos duales, técnica que ha sido utilizada en la presente investigación para evaluar la capacidad antagónica de algunas cepas contra $B$. glumae. El objetivo de la investigación fue evaluar el efecto que tienen las bacterias endófitas para el control de la enfermedad, permitiendo así generar nuevas técnicas que sean rápidas y confiables y que se puedan adoptar fácilmente en el manejo integrado de las enfermedades sin causar impacto ambiental.

\section{Materiales y métodos}

\section{Localización:}

El material obtenido para la realización del análisis, se colecto de la arrocera las Esmeralda S.A.S ubicada en el municipio de Jamundí, Valle del Cauca, Colombia, situado a 315'39 N 76³2'22" O 3.2608333333333 . Con una altitud media de 869 msnm temperatura promedio de $28^{\circ} \mathrm{C}$, humedad relativa del $82 \%$ y una precipitación anual de 1706 mm.

Cepa Burkholderia glumae Kurita \& Tabel, 1967: Para la realización del proyecto se utilizó una cepa de $B$. glumae, proveniente de un trabajo de investigación (datos sin publicar).

\section{Material para aislamiento de bacterias endófitas:} Se colectaron alrededor de 30 plantas al azar en varios estadios vegetativos, después de haber sido colectadas se llevaron al laboratorio donde se almacenaron en un refrigerador a una temperatura de $4^{\circ} \mathrm{C}$, para ser procesadas al día siguiente.

\section{Procesamiento de las muestras (Bacterias endófitas):}

Se realizaron cortes de tejido de las muestras para el proceso de desinfestación se tomaron porciones de (hojas, tallo y raíces) utilizando una solución de hipoclorito de sodio al $1.5 \%$ por un (1) minuto, lavado con agua destilada estéril por un (1) minuto, alcohol al $70 \%$ por un (1) minuto y finalmente dos lavados con agua destilada estéril por un (1) minuto.

Después de haber realizado el proceso de desinfección de las muestras, posteriormente se procedió a la siembra del material de estudio. En morteros completamente estériles se colocaron los tejidos y se maceraron con $10 \mathrm{ml}$ de agua destilada estéril, para garantizar la salida de las bacterias del tejido vegetal, hasta obtener una suspensión bacteriana, 
previamente se realizaron diluciones de $10^{-1}$ en tubos de ensayo con $9 \mathrm{ml}$ de agua destilada estéril y se le aplico vortex para homogenizar la solución bacteriana. Se tomaron $50 \mathrm{ul}$ y se sembraron por agotamiento en cajas de Petri con medio Agar Nutriente. Luego se incubaron a una temperatura de $28^{\circ} \mathrm{C}$ por 24 horas. Posteriormente se seleccionaron las colonias independientes y se sembraron nuevamente en medio Agar Nutriente por 24 horas hasta obtener colonias puras.

\section{Enfrentamientos duales}

Se realizaron dos técnicas de enfrentamiento dual con el fin de determinar, cuál de las bacterias endófitas obtenidas presentaban actividad antagónica sobre $B$. glumae realizando mediciones cada 48 horas.

Número 1: el primer ensayo se realizó, en cajas de Petri con medio Agar Nutriente y Agar King B, se realizó una siembra directa y por cada bacteria obtenida se llevaron a cabo tres repeticiones, trazando dos estrías perpendiculares en las cajas, en el extremo izquierdo se sembraron las bacterias endófitas y en el extremo derecho la bacteria patogénica. Luego se incubaron por un tiempo de 48 horas, a una temperatura de $28^{\circ} \mathrm{C}$. Comparado con el crecimiento del testigo de $B$. glumae.

Número 2: el segundo ensayo se realizó en cajas de Petri con medio Agar Nutriente y Agar King B, a una concentración de $1.0 \times 10^{-7}$, de acuerdo a la metodología establecida por Caldera (2011), se tomaron 100 microL de la solución bacteriana de $B$. glumae esparcidas en todas las cajas de Petri en ambos medios, después se ubicaron los inóculos de las bacterias endófitas en el centro de las cajas y se incubaron por un tiempo de 48 horas, a una temperatura de $28^{\circ} \mathrm{C}$, realizando constantemente observaciones. Comparado con el crecimiento del testigo de $B$. glumae.

\section{Perfil}

Morfología: para la realización de la caracterización morfológica, se tuvieron en cuenta las siguientes características como el tamaño (grandes, medianas o pequeñas) forma (Cocos, bacilos o espirilos), bordes (lisos o rugosos), elevación, consistencia (seca, cremosa, pegajosa), pigmentación y olor. Observadas al microscopio.

Perfil bioquímico: se llevaron a cabo las Tinciones de Gram, realizando siembras por agotamiento de las colonias individuales y puras, se incubarán por un periodo de 24 horas, a una temperatura de $28^{\circ} \mathrm{C}$. Previamente después de su crecimiento, se tomó una colonia y se realizó un frotis en una lámina portaobjetos, posteriormente se realizó la tinción, y cuando ya estuvieron completamente secas, se visualizaron en el microscopio para determinar si son bacterias Gram Positivas o Gram negativas. Después de haber determinado el tipo de pared celular de las bacterias, realizó la identificación de las bacterias mediante la utilización de las tiras API 50CHB con base en la colorimetría o cambio de color del medio de inoculación.

\section{Ensayo en campo}

El ensayo experimental se realizó en el lote de la Universidad Nacional de Colombia-Sede Palmira. Por lo cual se prepararon eras, para la siembra del cultivo de arroz. Se estableció un diseño experimental de bloques completamente al azar con dos repeticiones por cada estadio fenológico del cultivo de arroz. Como se indica en la Tabla 1.

Para realizar las inoculaciones de las bacterias endófitas se siguió la metodología establecida por (Pérez \& Chamorro, 2013) aplicadas a una concentración de $10^{-8} \mathrm{UFC} / \mathrm{ml}$. y para la aplicación de $B$. glumae se realizó basado en la metodología establecida por (Flórez \& Uribe, 2011) donde se utilizaron concentraciones de $1.0 \times 10^{-5}$.

El método de inoculación para las bacterias endófitas se realizó por aspersión aplicada en la lámina foliar y se prepararon $200 \mathrm{ml}$ de la solución bacteriana. Mientras para la inoculación de $B$. glumae, se realizó por inyección en la base del tallo. 
Tabla 1. BBCH Escala Extendida del cultivo de arroz.

\begin{tabular}{|c|c|}
\hline Código & Descripción \\
\hline \multicolumn{2}{|r|}{ Estadio principal 0. Germinación } \\
\hline 0 & Semilla seca \\
\hline 1 & Comienza la imbibición de la semilla \\
\hline 2 & Una hoja imperfecta (enrollada) emerge en la punta del coleóptilo \\
\hline 3 & Radícula (raíz embrional), emergencia de la semilla \\
\hline 4 & Radícula alargada, formando pelos radiculares y raíces secundarias \\
\hline 5 & Coleóptilo, emergido de la semilla \\
\hline 6 & Imbibición completa de la semilla \\
\hline \multicolumn{2}{|r|}{ Estadio principal 1. Desarrollo de las hojas } \\
\hline 7 & Hoja imperfecta desenrollada, visible la punta de la primera hoja verdadera \\
\hline 8 & Primera hoja, desplegada \\
\hline 9 & Novena hoja desplegadas \\
\hline 10 & Tercera Hoja desplegada \\
\hline 11 & Los estadios continúan \\
\hline 12 & Segundas hojas, desplegadas \\
\hline \multicolumn{2}{|r|}{ Estadio principal 5 . Salida de la panícula } \\
\hline 13 & Inicio de la emergencia de la panícula \\
\hline 14 & $20 \%$ de las panículas, emergidas \\
\hline 15 & $30 \%$ de las panículas, emergidas \\
\hline 16 & $40 \%$ de las panículas, emergidas \\
\hline 17 & Mitad de la emergencia de las panículas \\
\hline 18 & $60 \%$ de las panículas, emergidas \\
\hline 19 & $70 \%$ de las panículas, emergidas \\
\hline 20 & $80 \%$ de las panículas, emergidas \\
\hline 21 & Fin de la emergencia de las panículas \\
\hline \multicolumn{2}{|r|}{ Estadio principal 6. Floración (tallo principal) } \\
\hline 22 & Comienzo de la floración: anteras, visibles en lo alto de la panícula \\
\hline 23 & Plena floración: anteras, visibles en la mayoría de las espiguillas \\
\hline 24 & Fin de la floración: todas las espiguillas han terminado la floración \\
\hline 25 & La floración puede comenzar antes del estadio 55 \\
\hline \multicolumn{2}{|r|}{ Estadio principal 7. Formación del fruto } \\
\hline 26 & Madurez acuosa: los primeros granos han alcanzado la mitad de su tamaño final \\
\hline 27 & Lechoso temprano \\
\hline 28 & Lechoso medio: contenido del grano es lechoso \\
\hline 29 & Lechoso tardío \\
\hline
\end{tabular}




\section{continuación Tabla 1}

\begin{tabular}{c|l}
\hline \multicolumn{1}{c}{ Estadio principal 8. Maduración de frutos y semillas } \\
\hline 30 & Pastoso temprano \\
\hline 31 & Pastoso blando: contenido del grano, blando, pero seco; granos y glumas, todavía verdes \\
\hline 32 & Pastoso duro: contenido del grano sólido \\
\hline 33 & Madurez completa: grano duro \\
\hline 34 & Estadio principal 9. Senescencia \\
\hline 35 & Planta muerta, tallos se quiebran \\
\hline 36 & Partes cosechadas (estadio para señalar tratamientos de postcosecha) \\
\hline
\end{tabular}

Fuente. www.tecnoagricola.es.

\section{Resultados y discusión}

Con el material colectado en campo se realizó el proceso de desinfección y siembra de las muestras para realizar el aislamiento de las bacterias endófitas, de todas las muestras procesadas se obtuvieron alrededor de 24 colonias bacterianas totalmente purificadas. Posteriormente se llevó a cabo la evaluación a nivel del laboratorio, para determinar su potencial antagónico sobre $B$. glumae, utilizando la técnica de cultivo dual.

Enfrentamiento Dual $\mathrm{N}^{\circ} \mathbf{1}$ : de acuerdo con los resultados obtenidos, de las 24 cepas bacterianas evaluadas contra $B$. glumae no se observó ningún halo de inhibición generado sobre el crecimiento de la bacteria patogénica. Por lo tanto, la actividad antagónica fue nula.

Enfrentamiento Dual Na2: de acuerdo con los resultados obtenidos de las 24 cepas analizadas solo dos cepas presentaron efecto antagónico sobre $B$. glumae. En la cepa Numero 4 se observó un efecto antagónico sobre la bacteria patogénica, mostrando un halo de inhibición muy reducido, mientras que en la cepa Numero 18, se observa como la bacteria endófita parasita rápidamente a $B$. glumae deteniendo completamente su crecimiento.

Ensayo en campo: previo a las inoculaciones de las dos bacterias endófitas antagónicas y la bacteria patogénica $B$. glumae. Se realizaron evaluaciones semanalmente, donde no se visualizó ningún síntoma que pudiera estar asociado a la aparición de la enfermedad en las plantas, para los dos tratamientos evaluados. Las plántulas en estado de germinación, plántula y embuchamiento presentaron un buen desarrollo y crecimiento optimo asociado a la acción ejercida de las bacterias endófitas.

Caracterización Bioquímica: mediante el uso de la herramienta API web, se pudo calcular el porcentaje de aproximación de las especies del genero Bacillus, como se indica en la Tabla 2. Obteniendo como resultado con un porcentaje de aproximación del $99 \%$, el sistema índico que la Cepa C8 y C14, pertenecen a la especie Bacillus subtilis/amiloliquenfaciens - 99\% ID, como se observa en la Tabla 3. De acuerdo con lo descrito por los autores Manu y Morisaki, 2008, la especie Bacillus subtilis se encuentra reportada como bacteria endófita presente en los tejidos internos de las plantas de arroz, alojadas en las semillas y los tallos. Se caracterizan por poseer propiedades que ayudan al crecimiento y desarrollo óptimo de las plantas, además de que actúan como control biológico de algunas enfermedades, entre ella, al control de $B$. glumae.

Caracterización Morfológica: Cepa Numero 8: Poseen forma cilíndrica, son de color blanco, formando colonias grandes e irregulares, presentan el centro elevado en forma de un anillo, son de bordes ondulados, planas y una presentan consistencia cremosa. Cepa Numero 14: Poseen forma cilíndrica, son de color opaco, formando coIonias grandes de bordes irregulares presentan el centro elevado en forma de un anillo, son de bordes ondulados, planas y una presentan consistencia seca. 
Tabla 2. Identificación de Bacterias endófitas.

\begin{tabular}{c|l|c}
\hline Cepa & \multicolumn{1}{|c}{ Especie } & \% identificación \\
\hline C8 & Bacillussubtilis/amiloliquenfaciens & $99 \%$ \\
\hline C14 & Bacillus subtilis/amiloliquenfaciens & $99 \%$ \\
\hline
\end{tabular}

Tabla 3. Resultados de la caracterización bioquímica de los aislados antagonistas mediante tiras API 50CHB

\begin{tabular}{c|c|c|c|c|c|c|c|c|c|c|c|c|}
\hline $\begin{array}{c}\text { Prueba } \\
\text { Bioquímica }\end{array}$ & $\mathbf{C 8}$ & $\mathbf{C 1 4}$ & $\begin{array}{c}\text { Prueba } \\
\text { bioquímica }\end{array}$ & $\mathbf{C 8}$ & $\mathbf{C 1 4}$ & $\begin{array}{c}\text { Prueba } \\
\text { bioquímica }\end{array}$ & $\mathbf{C 8}$ & $\mathbf{C 1 4}$ & $\begin{array}{c}\text { Prueba } \\
\text { bioquímica }\end{array}$ & $\mathbf{C 8}$ & $\mathbf{C 1 4}$ \\
\hline 0 & + & + & INO & + & + & INO & + & + & INU & + & - \\
\hline GLY & + & + & MAN & + & + & MAN & + & + & MLZ & - & - \\
\hline ERY & - & - & SOR & + & + & SOR & + & + & RAF & + & + \\
\hline DARA & - & - & MDM & - & - & MDM & - & - & AMD & + & + \\
\hline LARA & + & + & MDG & + & + & MDG & + & + & GLYG & + & + \\
\hline RIB & + & + & NAG & - & - & NAG & - & - & XLT & - & - \\
\hline DXYL & + & + & AMY & + & - & AMY & + & - & GEN & - & + \\
\hline LXYL & - & - & ARB & + & + & ARB & + & + & TUR & - & - \\
\hline ADO & - & - & ESC & + & + & ESC & + & + & LYX & - & - \\
\hline MDX & - & - & SAL & + & + & SAL & + & + & TAG & - & - \\
\hline GAL & - & - & CEL & + & + & CEL & + & + & DFUC & - & - \\
\hline GLU & + & + & MAL & + & + & MAL & + & + & LFUC & - & - \\
\hline FRU & + & + & LAC & - & + & LAC & - & + & DARL & - & - \\
\hline MNE & + & + & MEL & + & + & MEL & + & + & LARL & - & - \\
\hline SBE & - & - & SAC & + & + & SAC & + & + & GNT & - & - \\
\hline RHA & - & - & TRE & + & + & TRE & + & + & & & \\
\hline DUL & - & - & 2KG & - & - & SKG & - & - & & \\
\hline
\end{tabular}

Control (0), Glycerol (GLY), Eritritol (ERY), D- Arabinosa (DARA), L- Arabinosa (LARA), Ribosa (RIB), D- Xylosa (DXYL), LXylosa (LXYL), Adonitol (ADO), B-Metil-D-Xylosida (MDX), Galactosa (GAL), Glucosa (GLU), Fructosa (FRU), Manosa (MNE), Sorbosa (SBE), Ramnosa (RHA), Dulcitol (DUL), Inositol (INO), Manitol (MAN), Sorbitol (SOR), 1-Metil-D-Manósido (MDM), 1-Metil-D-Glucósido (MDG), N-Acetol-Glucosamina (NAG), Amygdalina (AMY), Arbutin (ARB), Esculin (ESC), Salicin (SAL), Celobiosa (CEL), Maltosa (MAL), Lactosa (LAC), Melobiosa (MEL), Sucrosa (SAC), Trehalosa (TRE), Inulin (INU), Melecitosa

(MLZ), Rafinosa (RAF), Almidon (AMD), Glucógeno (GLYG), Xylitol (XLT), Gentiobiosa (GEN), D-turanosa (TUR), D-lyxosa

(LYX), D-tagatosa (TAG), D-fucosa (DFUC), L-fucosa (LFUC), D-arabitol (DARL), L-arabitol (LARL), Gluconato (GNT), 2-Keto-Gluconato (2KG), 5-Keto-Gluconate (5KG). 


\section{Conclusiones}

De las 24 colonias de bacterias endófitas aisladas del material vegetal, se encontraron en mayor proporción en tallos y semillas, de las cuales solo dos de ellas pertenecientes al género Bacillus, presentaron efecto antagónico contra B. glumae. Los ensayos realizados en campo para evaluar el efecto antagónico de las bacterias endofiticas sobre $B$. glumae, lograron demostrar que no hubo expresión de la bacteria patogénica en los diferentes estadios fenológicos de las plantas de arroz evaluadas, lo cual indica que las bacterias antagónicas en cierto modo ejercieron una barrera en la expresión de la enfermedad. Las bacterias endófitas presentes en las plantas desempeñan un papel importante para el buen crecimiento y desarrollo de un cultivo, permiten la fijación y asimilación de nutrientes esenciales para las plantas como Bacillussubtilis/amiloliquenfaciens.

\section{Literatura citada}

1. Cother, E. J., Noble D. H., Van de Ven R. J., Lanoiselet V., Ash G., Vuthy N., Visarto P. \& Stodart B. (2010). Bacterial pathogens of rice in the Kingdom of Cambodia and description of a new pathogen causing a serious sheath rot disease. Plant Pathology 59, 944-953.

2. Cottyn, B., Cerez, M. T., Van Outryve, M. F., Barroga, J., Swings, J. \& Mew, T. W. (1996). Bacterial diseases of rice. I. Pathogenic bacteria associated with sheath rot complex and grain discoloration of rice in The Philippines. Plant Dis. 80, 429-437.

3. Chien, C. C., Chang, Y. C., Liao, Y. M. \& Ou, S. H. (1983). Bacterial grain rot of rice-a new disease in Taiwam. Journal of Agricultural Research of China. 32(4), 360-366.

4. Cho, H.S., S.Y. Park, C.M. Ryu, J.F. Kim, J.G. Kim \& S.H. Park. (2007). Interference of quorum sensing and virulence of the rice pathogen Burkholderia glumae by an engineered endophytic bacterium. FEMS Microbiology Ecology 60(1), 14-23.

5. Elbeltagy, A.; Nishioka, K.; Sato, T.; Suzuki, H.; Ye, B.; Hamada, T.; Isawa, T.; Mitsui, H. \& Minamisawa, K. (2001). Endophytic colonization and in plant nitrogen fixation by a Herbaspirillum sp. isolated from wild rice species. Appl Environ Microbiol. 67, 5285- 5293.

6. Flemming, H.C. (1993). Biofilms and environmental protection. Water Sci. Technol. 27, 1-10.

7. Flórez, Z.N.M.V. \& Uribe, V.D. (2011). Determinación de la infección de Burkholderia glumae en semillas de variedades comerciales colombianas de arroz. Rev Fac Nac Agron 64(2), 6093-6104.
8. Gilbert, P.; Das, J. \& Foley, I. (1997). Biofilms susceptibility to antimicrobials. Adv. Dent. Res. 11, 160-167.

9. González, A., Graterol, E., Arnao, E., Torres, E., Acevedo, M. \& Mosquera, G. (2011). Primer reporte de Burkholderia glumae causante de la pudrición bacteriana de la panícula del arroz en Venezuela. Fitopatología Colombiana 35(1), 81.

10. Goto K. \& Ohata K. (1956) New bacterial diseases of rice (brown stripe and grain rot). Ann Phytophathol Soc Jpn 21, 46-47.

11. Hallman J., Quadt-Hallman A., Mahaffee W.F. \& Kloepper J.W., (1997). Bacterial endophytes in agricultural crops. Canadian Journal of Microbiology 43, 895-914.

12. Hernandez, A.; Rives, N. \& Heydrich, Y.M. (2004). Caracterización de la comunidad microbiana y endófita asociada al cultivo del arroz variedad J- 104. En: Congreso Científico del INCA (14:2004, nov 9-12, La Habana).

13. Iwai, T., Kaku, H., Honkura, R., Nakamura, S., Ochiai, H., Sasaki, T. \& Ohashi, Y. (2002). Enhanced resistance to seed-transmitted bacterial diseases in transgenic rice plants overproducing an oat cell-wall-bound thionin. Mol. Plant-Microbe Interact. 15, 515-521.

14. Jayasinghearachchi H.S. \& Seneviratne G. (2006). Fungal solubilization of rock phosphate is enhanced by forming fungal-rhizobial biofilms. Soil Biol Biochem 38, 405-408.

15. Jeon, Y., Kim, J., Kim, S., Kang, Y., Nagamatsu, T. \& Hwang, I. (2003). Toxoflavin produced by Burkholderia glumae causing rice grain rot is responsible for inducing bacterial wilt in many field crops. Plant Dis. 87, 890-895

16. León-Aristizábal, G. (2011). Aspectos de la circulación atmosférica de gran escala sobre el noroccidente de Suramérica asociada al ciclo ENOS 2009-2010 y sus consecuencias en el régimen de precipitación en Colombia. In Boletín Meteorologico IDEAM ENOS 20092010. 20 p.

17. Mogi, S. (1988). Detection and diagnosis of pathogen for bacterial grain rot (Pseudomonas glumae) on rice. 5th Int. Congress of Plant Pathology. Section XIII, 3-3. p.403

18. Nandakumar, R., Rush, M., Shahjahan, A.; O’Reilly, K. \& Groth, D. (2005). Bacterial panicle blight of rice in the southern United States caused by Burkholderia glumae and B. gladioli. Phytopathology 95 (suppl.), S73.

19. Nandakumar, R., Rush, M. C. \& Correa, F. (2007). Association of Burkholderia glumae and B. gladioli with panicle blight symptoms on rice in Panama. Plant Dis. 91, 767.

20. Nandakumar, R., A.K.M. Shahjahan, X.L. Yuan, E.R Dickstein, D.E. Groth, C.A. Clark, R.D. Cartwright \& M.C. Rush. (2009). Burkholderia glumae and B. gladioli cause bacterial panicle blight in rice in the southern United States. Plant Dis. 93(9), 896-905.

21. Nieves, C. (1999). Bacterial grain rot. In: Seed-Borne Bacterial Diseases. 8th Revised Edition. Danish Government Institute of Seed Pathology for Developing Countries. pp. 108-113. 
22. Ou, S.H. (1985). Rice diseases. CAB Commonwealth Mycological Institute, Kew Surrey, England. 380p.

23. Pérez, A.F., Pérez, C.R. \& Chamorro, C.M. (2013). Bacterias endófitas asociadas a cultivo de arroz con actividad antimicrobiana sobre Burkholderia glumae. Rev. Asoc. Col. Cienc. (Col.), 25, 31-40.

24. Pérez, C.A. \& Chamorro, A.L. (2013). Bacterias endófitas: Un nuevo campo de investigación para el desarrollo del sector agropecuario. Rev. Colombiana cienc. Anim. 5(2), 439-462.

25. Shahjahan, A. K., Rush, M. C., Groth, D. \& Clark, C. (2000). Panicle blight research points to a bacterial cause. Rice J. 103, 26-28.

26. Saichuk, J., Harrel, D., Fontenot, K., Groth, D., Hollier, C., Hummel, N., Linscombe, S., Sha, X.; Stout, M.:Webster, E. \& White, L. (2011). Rice varieties and management tips. LSU AgCenter Research \& Extension. Recuperado de: www.Isuagcenter.com/en/crops_livestock/ Crops/rice/Publications/

27. Sayler, R., R. Cartwright, \& Y. Yang. (2006). Genetic characterization and Real time PCR detection de $B$.glumae a newly emerging bacterial pathogen of rice in USA. Plant Dis. 90, 603-610.
28. Thakuria, D.; Talukdar, N. C.; Goswami, C.; Hazarika, S.; Boro, R. C. \& Khan, M. R. (2004). Characterization and screening of bacteria from rhizosphere of rice grown in acidic soils of Assam. Current Science 86(7), 978-985.

29. Trung, H. M., Van, N. V., Vien, N. V., Lam, D. T. \& Lien, M. (1993). Occurrence of rice grain rots disease in Vietnam. Int. Rice Res. Notes 18:30.

30. Yang, X. (2004). Identification of bacterial pathogens causing panicle blight of rice in Louisiana. Thesis M.Sc. The Department of Plant Pathology and Crop Physiology, Louisiana State University and Agricultural and Mechanical College, USA.

31. Zhu B., Lou M., Huai Y., Xie G., Luo J. \& Xu L. (2008). Isolation and identification of Burkholderia glumae from symptomless rice seeds. Rice Science 15(2), 145-149.

32. Zeigler, R. S. \& Álvarez, E. (1989). Grain discoloration of rice caused by Pseudomonas glumae in Latin America. Plant Dis. 73, 368.
Conflicto de Intereses Los autores declaran no tener ningún conflicto de intereses

Recibido: Marzo 02 de 2017 Aceptado: Abril 21 de 2017 